\title{
FMEA and FTA Analyses of the Adhesive Joining Process using Electrically Conductive Adhesives
}

\author{
E. Povolotskaya, P. Mach
}

\begin{abstract}
This paper introduces a formulation of appropriate risk estimation methods that can be used for improving of processes in the electronics area. Two risk assessment methods have been chosen with regard to the specifics of adhesive joining based on electrically conductive adhesives. The paper provides a combination of a failure mode and effect analysis (FMEA) and fault tree analysis (FTA) for optimizing of the joining process. Typical features and failures of the process are identified. Critical operations are found and actions for avoiding failures in these actions are proposed. A fault tree has been applied to the process in order to get more precise information about the steps and operations in the process, and the relations between these operations. The fault tree identifies potential failures of the process. Then the effects of the failures have been estimated by the failure mode and effect analysis method. All major differences between failure mode and effect analysis and fault tree analysis are defined and there is a discussion about how to use the two techniques complement each other and achieve more efficient results.
\end{abstract}

Keywords: failure mode and effect analysis, fault tree analysis, adhesive joining, electrically conductive adhesives.

\section{Introduction}

Electrically conductive adhesives (ECAs) are becoming increasingly important in the electronics industry. These materials are used in two main areas of electronics packaging - in mounting of heat sensitive components such as LCDs, and in mounting ultrafine pitch electronic packages [1].

ECAs create a permanent electrical and mechanical connection between the pad and the component lead. Adhesives on an epoxy basis filled with silver conductive particles are mainly used. The curing temperature is lower than the soldering temperature of lead-free solders. The electrical conductivity depends on the concentration of conductive particles in the resin, on the shape and the material of these particles [2].

An appropriate surface pretreatment of the joined parts and detailed control of the filler through an analysis of the grains are necessary to achieve of good electrical, mechanical and thermal properties of adhesive joints [3]. To achieve parameters adhesive joints that are comparable with soldered joints it is necessary to optimize the process of adhesive joining.

The electrical resistivity of adhesives, electrical noise and the nonlinearity of the current vs. voltage characteristic are higher than these parameters for lead-free solders. The mechanical properties and climate resistivity of ECAs are also worse than these of solders [4].

There are many parameters that influence the quality of adhesive joints in the process of adhesive joining. Optimization of this process requires the use of proper quality control tools such as failure mode and effect analysis (FMEA) and fault tree analysis (FTA). These analyses make an examination of the process critical parameters possible.

FMEA is a technique for analyzing the occurrence of process failures and their effect on the result of a process [7]. Currently, FMEA is a widely used method for risk assessment in industrial processes. This method is primarily adapted for material and equipment failures. There are four basic types of FMEA: process FMEA, system FMEA, design FMEA and service FMEA. FMEA produces risk priority numbers (RPNs) as outcomes. RPNs are obtained for each failure that can occur in a process.

An RPN is a multiplication of the severity, occurrence and detection numbers for each failure. Severity of failure shows the level of seriousness of the failure. The occurrence number represents how often the failure occurs and the detection number indicates the level of visibility of the failure. The purpose of FMEA is to reduce the RPN by reducing one, two or all three numbers in order to improve the process and ensure the non-appearance of such errors subsequently. The appearance of the failure can be reduced by improving the technical documentation requirements in the process to eliminate the causes of failures or reduce their frequency. Detection can be reduced by offering new or improved assessment methods or by offering additional equipment for detection. Several examples of FMEA implementation for industrial processes are presented in [12-15]. 
A fault treeforms the basis for logical-probabilistic models of system failure causality, failures of its elements and other events or impacts [8]. This method is based on sequences and combinations of disturbances and faults [9]. Thus it is a multilevel structure or diagram of causal relationships [10]. FTA provides a common vision of the process, components, and how these components are related. This makes it easy to identify the defects arising in the process. It also provides a way for proposing step-by-step improvements to prevent defects and errors and for making a troubleproof process. Several examples of a successful combination of fault tree analysis and failure mode and effect analysis methods for application in industrial processes are shown in [10,16-19].

This paper presents the use of FTA and FMEA for optimizing the joining process when electrically conductive adhesives (ECA) are used.

\section{Theoretical background}

\section{$2.1 \quad$ Basic risk analysis methods}

Generally, risk is the possibility of the occurrence of certain undesirable events that initiate various types of failures. Risk analysis is used to find causes of failures and to prevent the occurrence of these failures in the future. The results of risk analysis can be used for process optimization.

Risk analysis is divided into two complementary types:

1. Qualitative.

2. Quantitative.

The task of qualitative analysis is to identify the risk areas in a process, types of risks, and the factors causing the risks. This is done in various ways, for example, by an expert, by brainstorming and so on. Quantitative analysis enables the level of effect to be quantified for each type of risk.

Basic methods for risk analysis are as follows:

1. Analogies.

2. Expert methods.

3. Statistical methods.

4. Modeling, etc.

The analogy approach is focused on an examination of analogies among data obtained from a range of sources. Expert methods are used to collect the opinions of qualified specialists. A statistical approach to risk analysis uses various types of statistical methods to process data that has been obtained experimentally. The simulation is based on calculating various types of models and on testing or these models in various situations.

The followings are some of the most commonly used risk analysis methodologies [5]:

1. Structured What-If Technique (SWIFT).

2. Fault tree analysis (FTA).
3. Event tree analysis (ETA).

4. Failure modes and effects analysis (FMEA).

Two expert methods for risk analysis - fault tree analysis (FTA) and failure mode and effect analysis (FMEA) - were used for an analysis of a conductive adhesive joining process [22].

\subsection{Fault tree analysis}

FTA is a very powerful systematic way which is widely used for estimating process quality. Starting from the top event, the fault-tree method uses a Boolean algebra and logical modeling to make a graphical representation of the relations among various failure events at different levels of the process (Figure 1) [21].

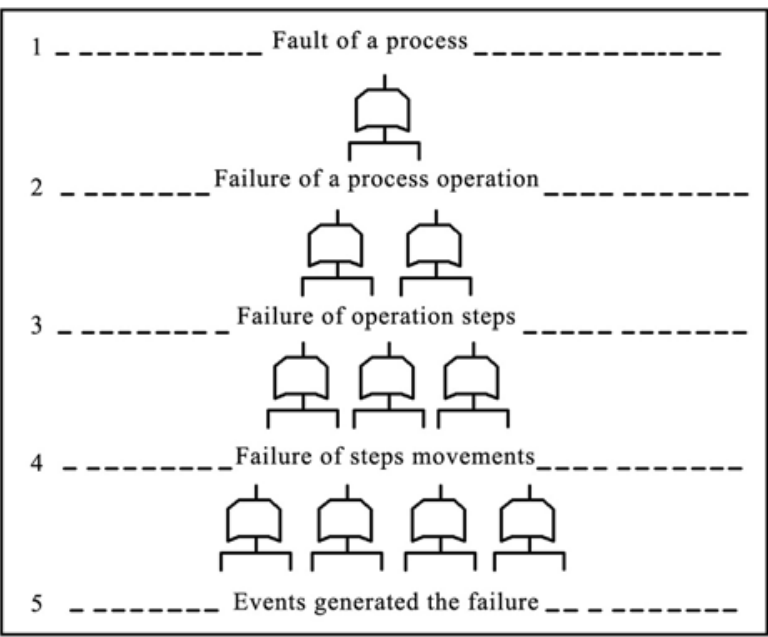

Fig. 1: Typical fault tree

In this technique, deductive logic is used. It enables the root causes of the failure events of a process to be found. This type of logic helps to establish a clear and detailed scheme of relationships between steps or events in the process that can affect their quality.

The contribution of the fault tree is as follows:

- Allows potential failure parts of the process to be seen in detail.

- Helps identify failures deductively.

- Enables a qualitative or quantitative analysis of the process to be made.

- The method can focus on individual parts of the process, and can extract specific failures.

- It clearly represents the behavior of the process. The main advantage of the fault tree (in comparison with other methods) is that the analysis is limited to identifying only those events of the process which lead to a specific process failure.

The disadvantages of fault trees are as follows:

- Implementation of the method requires considerable inputs, because more process details leads 
to a geometric increase in the analyzed area, and the number of influencing events grows correspondingly.

- A fault tree is a Boolean logic diagram, which shows only two states: working and failed.

- It is difficult to estimate the state of partial failure of the process parts, because use of the method generally indicates that the process is either in good condition or in a faulty state.

- It requires a reliability specialist with deep knowledge of the process.

\subsection{Failure mode and effect analysis}

The FMEA method is applied in addition to the FTA technique. The Failure Mode and Effects Analysis (FMEA) is a widely used analytical tool. It is especially useful in connection with reliability, maintainability and safety analyses.

The main goals of the technique are to determine:

- Possible failures (defects) of the process, their causes and consequences;

- The criticality of the effects on the process $(\mathrm{S})$, the probability of occurrence (defects) (O) and their detectability (D).

- Generalized assessments of the functionality of the process - calculation of RPN. Ten-point or five-point rating scales are often used for occurrence, detection and severity numbers. A rule of thumb is usually used for the risk priority number. This means that a serious look has to be taken at RPNs higher than 125 . When a tenpoint scale is used [3].

A special team is set up to conduct FMEA. The values of $\mathrm{S}, \mathrm{D}, \mathrm{O}$, and $\mathrm{RPN}$ are determined by expert estimates [22].

FMEA of the production process covers the stage of technical preparation of equipment and materials for the process to be started. It ends before the direct work begins [22].

\section{Experimental part}

Before the risk analysis is started, it is necessary to define the main steps in the process. A flow-chart of the process of electrically conductive adhesive joining is shown in Figure 2.

Failures of adhesive joints are mostly connected with their mechanical and/or electrical properties. A table of failure resistance and nonlinearity of the current vs. the voltage characteristic of an adhesive joint is shown in Table 1. The structure of the total resistance of an adhesive joint is shown in Figure 3.

Here R1 represents the resistances between the component lead and the adhesive, R2 represents the resistance of adhesive, and $\mathrm{R} 3$ represents the resistance between the pad and the adhesive.

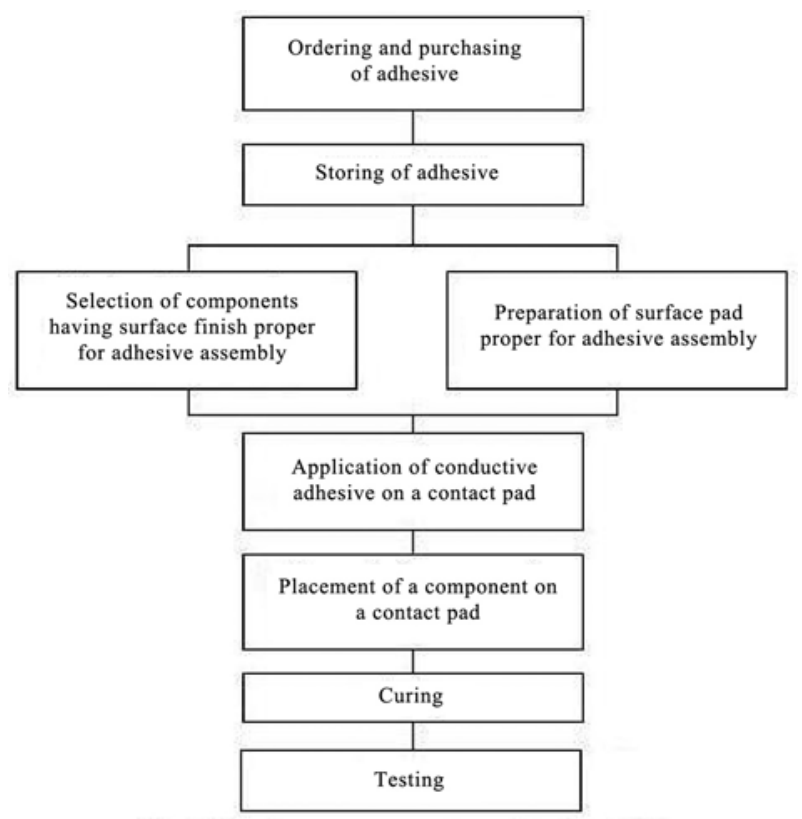

Fig. 2: Flow-chart for a joining process based on ECA

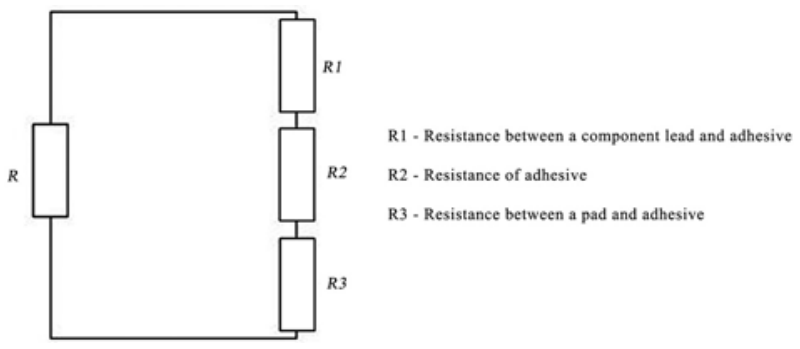

Fig. 3: Total resistance of an adhesive joint

Table 1: Adhesive joining characteristics (the values are valid for joining components of dimension type 1206)

\begin{tabular}{|l|l|l|}
\hline & Typical value & Failure value \\
\hline Resistance $(\mathrm{R})$ & $20 \mathrm{~m} \Omega$ & $\geq 40 \mathrm{~m} \Omega$ \\
\hline Nonlinearity $(\mathrm{U})$ & $10 \mu \mathrm{V}$ & $\geq 25 \mu \mathrm{V}$ \\
\hline
\end{tabular}

Parts of the assembly process which influence the values of these resistances are examined and analyzed for the risk of the occurrence of potential failures.

Deductive approach (FTA) and inductive approach (FMEA) are reviewed.

The first step in the process of an examination of adhesive joining using a fault tree analysis is to identify the main undesirable events. To define such an event, it is necessary to define still acceptable values for joint resistance, nonlinearity of the current vs. voltage characteristic of the joint, shear strength, tensile strength, etc. Typical and failure values of electrical adhesive joining characteristics, such as joint resistance and joint nonlinearity of the current vs. voltage characteristic, are shown in Table 1 .

These events become the top-event of a fault tree. 
Table 2: Influence of basic fault events on the properties of the adhesive

\begin{tabular}{|l|c|c|c|c|c|}
\hline FAULTY ECA JOINT & $\begin{array}{c}\text { Low } \\
\text { mechanical } \\
\text { resistivity }\end{array}$ & $\begin{array}{c}\text { High } \\
\text { electrical } \\
\text { resistance }\end{array}$ & $\begin{array}{c}\text { High } \\
\text { nonlinearity } \\
\text { of adhesive }\end{array}$ & $\begin{array}{c}\text { High } \\
\text { noise }\end{array}$ & FTA code \\
\hline Improper material of a lead & & $\times$ & & $\times$ & FCU1 \\
\hline Improper material of a pad & & $\times$ & & FCU2 \\
\hline Improper surface finish of a lead & $\times$ & $\times$ & $\times$ & FCU3 \\
\hline Improper surface finish of a pad & $\times$ & $\times$ & $\times$ & $\times$ & FCU4 \\
\hline Inappropriate curing & $\times$ & $\times$ & $\times$ & FCU5 \\
\hline Inappropriate storing & $\times$ & $\times$ & & FCU6 \\
\hline Inappropriate type of resin & & & $\times$ & $\times$ & FCU7 \\
\hline Inappropriate concentration of filler particles & $\times$ & $\times$ & $\times$ & & $\times$ \\
\hline Inappropriate viscosity & & & FCU8 \\
\hline
\end{tabular}

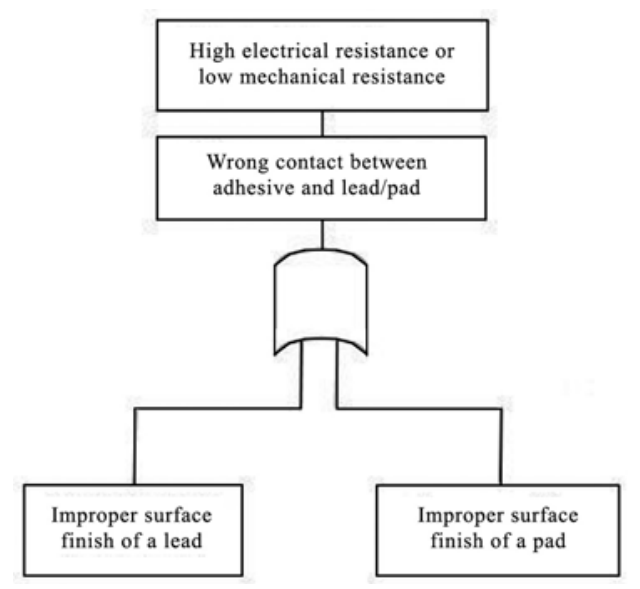

Fig. 4: FTA for joints formed by ECA

The second step is to identify of events directly related to the top-event. This is a repeatable process and can be continued until we reach the basic events that cause the top-event. Fault tree analysis (FTA) is generally performed using a logical structure of AND and OR gates. In the case of the joining process based on electrically conductive adhesive (ECA), each basic faulty event, alone, can cause one or more failures of an adhesive joint, so instead of grouping them under gates, we used a tabular representation of FTA (Table 2).

As a result of applying the FTA method to adhesive joining we found the weakest parts of the process. To obtain a better understanding of the failures, we applied FTA to each type of typical joint failure. Fault trees are presented in Figures 4, 5 and 6 .

Variance of the electrical resistance sometimes appears in joint of this type. It can be caused by improper surface finish of the pad and the component lead by faulty placing of a component or by using an adhesive with faulty consistency. Figure 7 shows a more detailed representation of the joint.
When the FTA has been performed, an inductive method such as failure mode and effect analysis (FMEA) is applied to the joining process in order to analyze the significance of various types of failures. With the help of FMEA, a potential failure mode in the process is analyzed to define the effect on the result of the process and to classify each potential failure mode according to severity. In the process considered here, we used Process FMEA in an original functional approach [20].

In this approach, each step in the process performs a number of events which can be determined as outputs. The outputs are listed and analyzed.

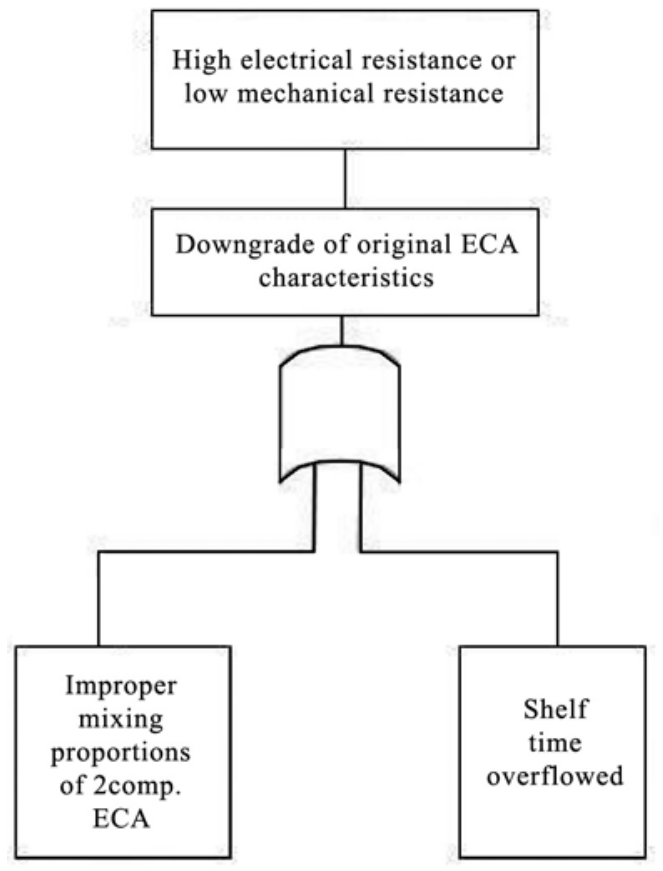

Fig. 5: FTA for joints formed by ECA 


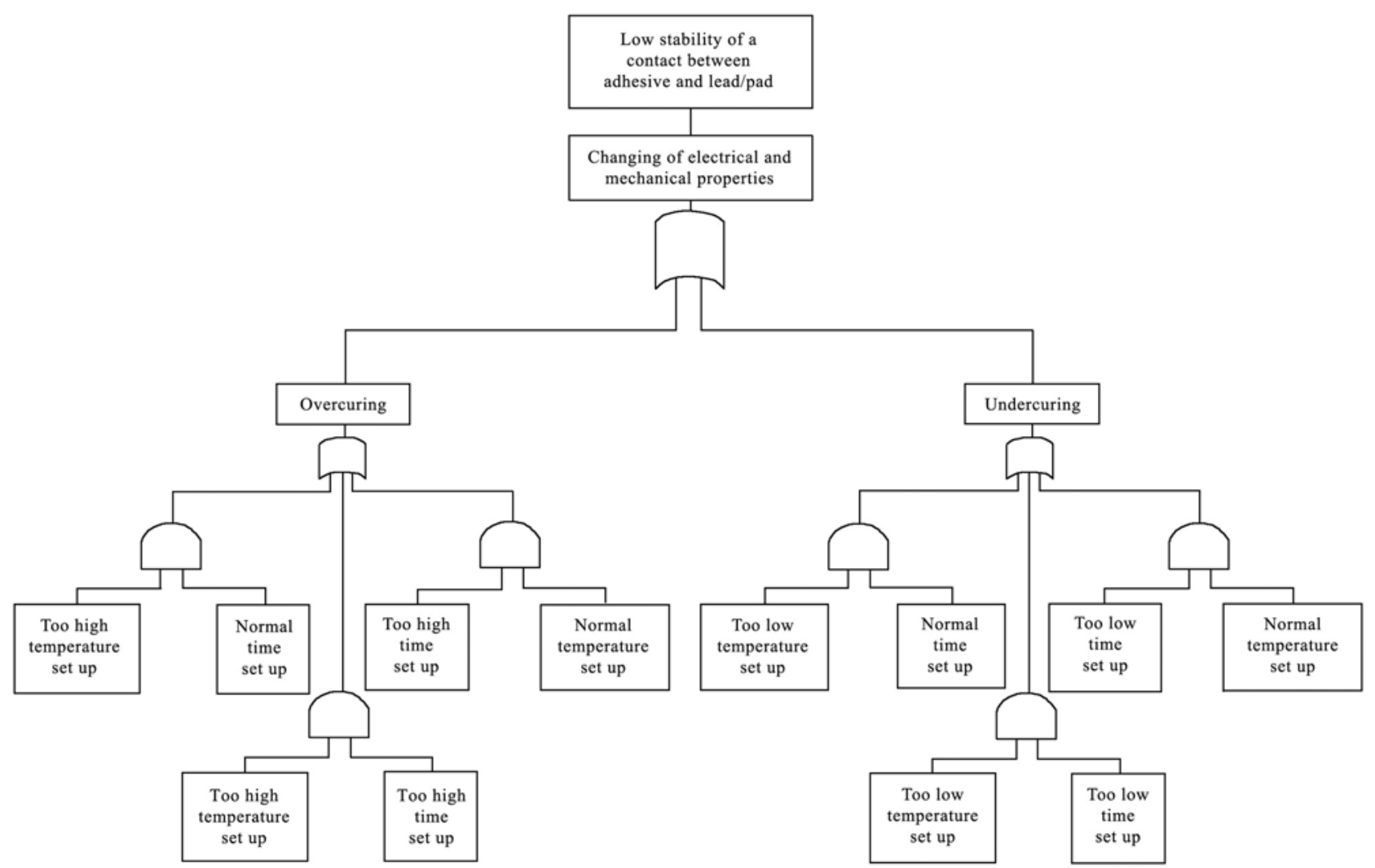

Fig. 6: FTA for joints formed by ECA

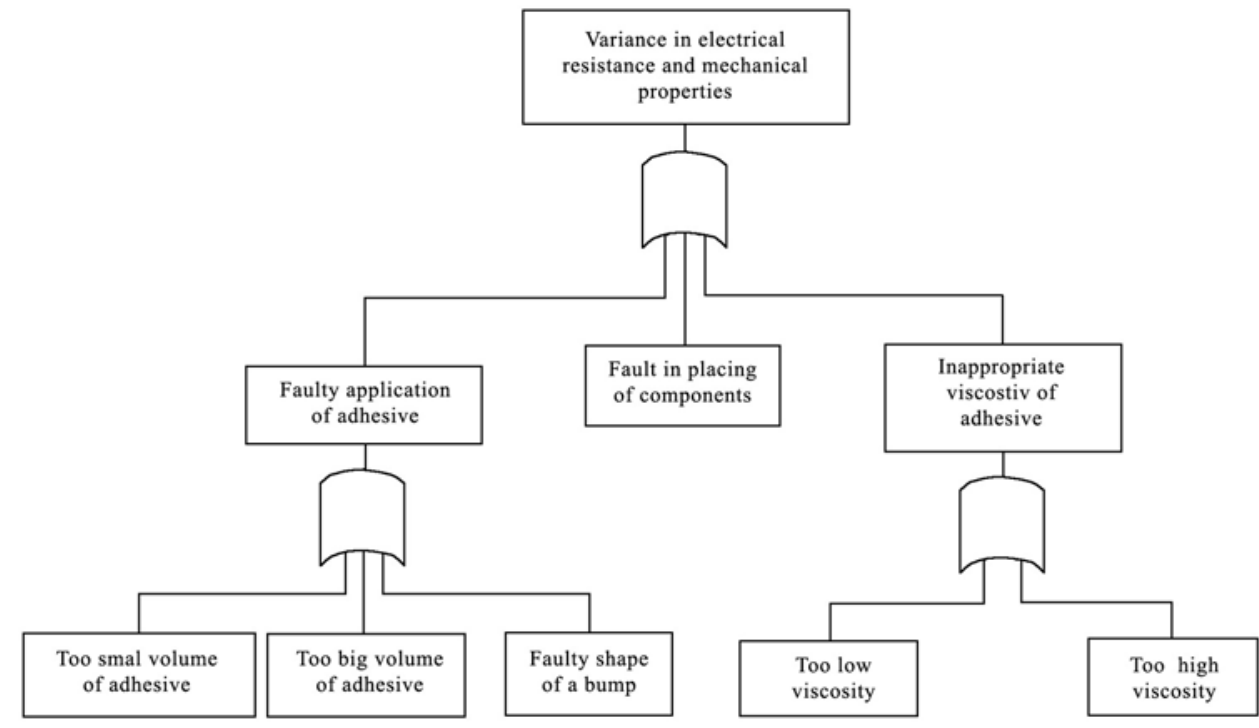

Fig. 7: FTA for joints formed by ECA

In our approach, we used the list of failures, i.e. events which cause the top-event, defined during the FTA analysis and for each undesirable event we define:

- Basic causes of failures,

- Specific features of the process,

- Severity numbers of failures(S): an assessment of the seriousness of the effects on the failure process,
- Number of occurrences of failures (O): an assessment of the likelihood that a failure will occur,

- Detection number of failures (D): assessment of whether current control methods detect the causes of failures on an appropriate level,

- Risk priority numbers (RPN): multiplication of detection, occurrence and severity numbers. This is used to set priorities for failures on pro- 
Table 3: Part of the failure mode and effect analysis table for joints formed by ECA

\begin{tabular}{|c|c|c|c|c|c|c|c|c|c|}
\hline \multirow{3}{*}{ 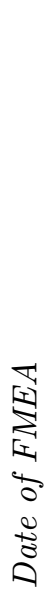 } & \multirow{3}{*}{ 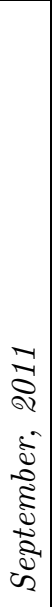 } & \multirow{3}{*}{ 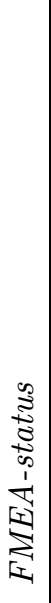 } & \multirow{3}{*}{ 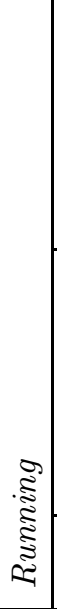 } & 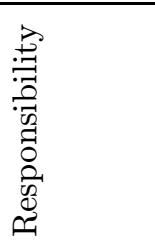 & & & & & \\
\hline & & & & 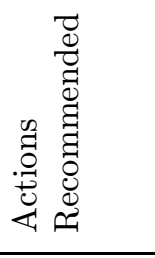 & 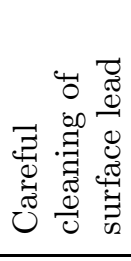 & 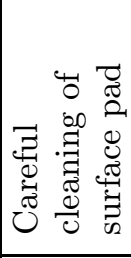 & 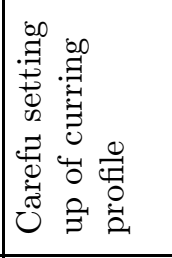 & 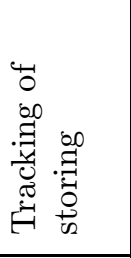 & \\
\hline & & & & $\simeq$ 口 Z & $\stackrel{\curvearrowright}{\sim}$ & $\underset{\sim}{\sim}$ & $\stackrel{N}{i}$ & $\stackrel{\infty}{\sim}$ & \\
\hline \multirow{5}{*}{ 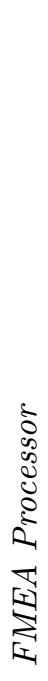 } & \multirow{5}{*}{ 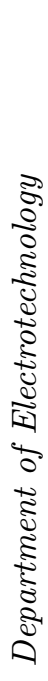 } & \multirow{5}{*}{ 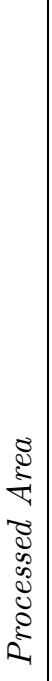 } & \multirow{5}{*}{ 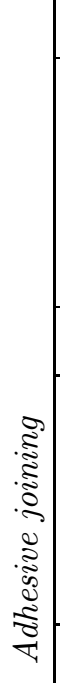 } & A & $\nabla$ & $\nabla$ & $\infty$ & $N$ & \\
\hline & & & & 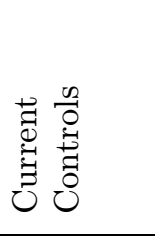 & 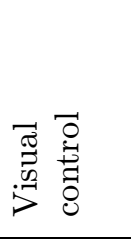 & 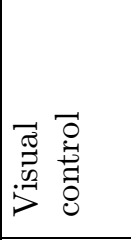 & 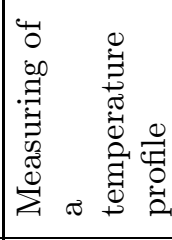 & 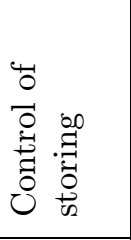 & 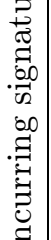 \\
\hline & & & & 0 & 0 & 0 & $m$ & $\infty$ & 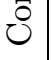 \\
\hline & & & & 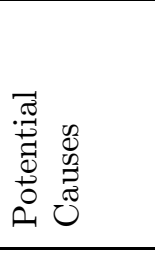 & 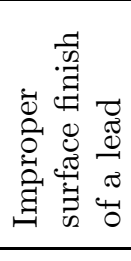 & 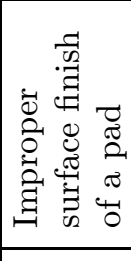 & 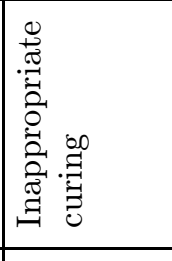 & 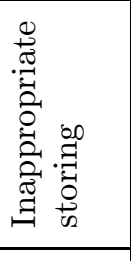 & \\
\hline & & & & U & $\infty$ & $\infty$ & $\infty$ & $\infty$ & \\
\hline & \multirow{3}{*}{ 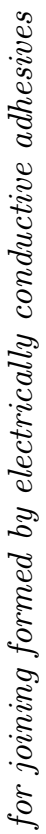 } & & \multirow{4}{*}{ 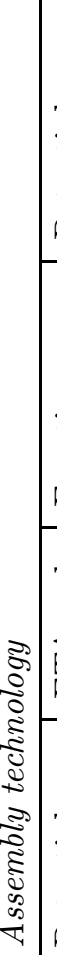 } & 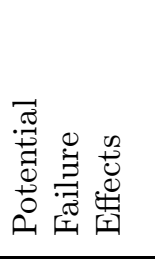 & 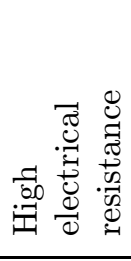 & 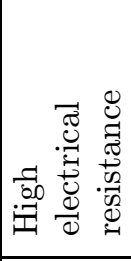 & 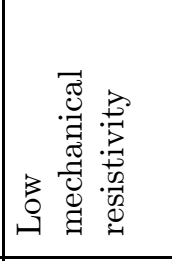 & 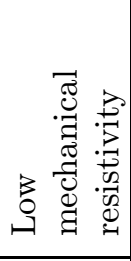 & \\
\hline & & & & 泀 & 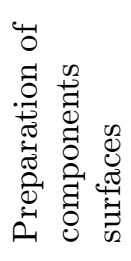 & 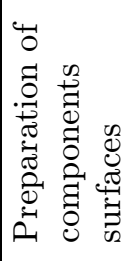 & 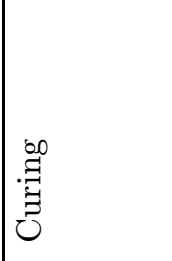 & 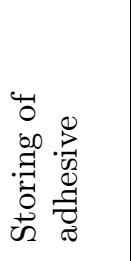 & \\
\hline & & $\pi$ & & 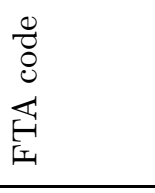 & 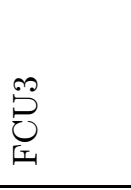 & 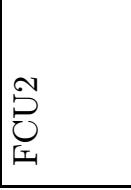 & 邑 & $\begin{array}{c}0 \\
\varrho \\
\bigcup_{1}\end{array}$ & $\underset{\Xi}{\Xi}$ \\
\hline & 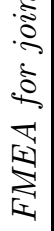 & 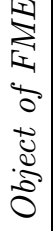 & & 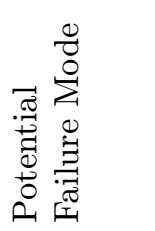 & 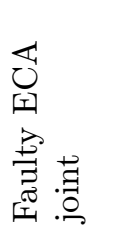 & & & & 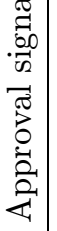 \\
\hline
\end{tabular}


cess levels, and to establish what requires additional quality planning,

- Corrective actions,

- Checks on corrective actions.

Parts of the output of this analysis of the Faulty ECA Joint failure mode are shown in Table 3.

\section{Conclusion}

The outcome of this approach is a reliability analysis realized through the interaction of the FMEA and FTA reliability tools. Each of these risk analysis methods has advantages, which enable the technological process to be investigated and help to observe the process more clearly from different points of view. The FMEA method in general is a library of all possible potential failures and their consequences, whereas FTA enables a detailed analysis of logical and temporal relationships that lead to a failure, taken over the top of the tree. The application of these two methods to the process, complementing each other, provides deeper information than applying the methods separately. As a consequence of this approach, more efficient results have been achieved. The most significant steps in forming high-quality adhesive joints are the preparation of the pad and the lead surfaces. Preventive measures to avoid failures have been proposed.

\section{References}

[1] John, H. L., Wong, C. P., Ning, C. L., Ricky Lee, S. W.: Electronics manufacturing with leadfree, halogen-free and conductive-adhesive materials. New-York : McGraw-Hill, Steve Chapman, 2003.

[2] Duraj, A.: Using of Electrically Conductive Adhesives for Bonding in Electrical Engineering. Prague : Czech technical university in Prague, 2001.

[3] Charles, A., Happer, M., Miller, M.: Electronic packaging, microelectronics, and interconnection dictionary. New-York : McGraw-Hill, 1993.

[4] Ageeva, N. D., Vinakovskaya, Y. U., Lifanov, V. N.: Electrotechnical material engineering. Vladivostok : DVGTU, 2006.

[5] Vose, D.: Risk Analysis: A Quantitative Guide. 3rd edition. England : John Wiley and songs, Ltd, 2008.

[6] Stamatis, D. H.: Failure mode and effect analysis: FMEA from theory to execution. 2nd ed. p.cm. Visconsin : ASQ Quality Press, 2003.
[7] McDermott, R. E., Mikulak, R. J., Beauregard, M. R.: The basics of FMEA. $2^{\text {nd }}$ edition. New York : Taylor \& Francis Group, LLC, 2009.

[8] Bilal, M. A.: Risk analysis in engineering and economics. Florida: CRC Press LLC, 2003.

[9] ICS 03.100.01, Czech technical standard ISO 31000:2009. Risk management - Principles and guidelines, 2010.

[10] Queiroz, S. R., Álvares, A. J.: FMEA and FTA Analysis for Application of the Reliability Centered Maintenance Methodology: Case Study on Hydraulic Turbines. Symposium Series in Mechatronics, 3, 2008, p. 803-812.

[11] Tichy, M.: Risk control. Analysis and management. Prague : C. H. Beck, 2006.

[12] Cassanelli, G., Mura, G., Cesaretti, F., Vanzi, M., Fantini, F.: Reliability Predictions in Electronic Industrial Applications. Microelectronics Reliability, 45, 2005, p. 1321-1326.

[13] Douglas, W. B., Patrick, W. K., Carl, S. B., Michael, J. R.: Electronic Prognostics - A Case Study Using Global Positioning. Microelectronics Reliability, 47, 2007, p. 1874-1881.

[14] Abdul-nour, G., Beaudoin, H., Ouellet, P., Rochetie, R., Lambert, S.: A Reliability Based Maintenance Policy; a Case Study. Computers and Industrial Engineering, 35 (3-4), 1998, p. 591-594.

[15] Scipioni, A., Saccarola, G., Centazzo, A., Arena, F.: FMEA Methodology Design, Implementation and Integration with HACCP System in a Food Company. Food Control, 13, 2002, p. $495-501$.

[16] Han-Xiong, L., Ming, J. Z.: A Hybrid Approach for Identification of Root Causes and Reliability Improvement of a Die Bonding Process - a Case Study. Reliability Engineering and System Safety, 64, 1999, p. 43-48.

[17] Ortmeier, F., Reif, W., Schellhorn, G.: Formal Safety Analysis of a Radio-Based Railroad Crossing Using Deductive Cause-Consequence Analysis (DCCA). Report D-86135. Augsburg : Lehrstuhl Für Softwaretechnik und Programmiersprachen, Universität Augsburg, 2005.

[18] Gasanelli, G., Fantini, F., Serra, G., Sgatti, S.: Reliability in Automotive Electronics; a Case Study Applied to Diesel Engine Control. Microelectronics Reliability, 43, 2003, p. 1411-1416. 
[19] Moser, T., Melik-Merkumians, M., Zoitl, A.: Ontology-based Fault Diagnosis for Industrial Control Applications. Report 11662353. Bilbao : Vienna University of Technology, 2010.

[20] Vesely, W. E., Goldberg, F. F., Roberts, N. H., Haasl, D. F.: Fault Tree Handbook. Washington, D.C. : Mail Stop SSOP, 1981.

[21] Ching-Torng, L., Mao-Jiun, J. W.: Hybrid Fault Tree Analysis Using Fuzzy Sets. Reliability Engineering and System Safety, 58, 1997, p. 205-213.
[22] Kane, M. M., Ivanov, B. V., Koreshkov, V. N., Skchirtladze, A. G.: Systems, methods and tools of quality management. Saint Petersburg : Piter Press, 2009.

Evgenia Povolotskaya

Pavel Mach

E-mail: povolevg@fel.cvut.cz

Czech Technical University in Prague 